\title{
Identification and Detection of Fusarium striatum as a New Record of Pathogen to Greenhouse Tomato in Northeastern America
}

Lauriane M. Moine and Caroline Labbé, Département de Phytologie, Faculté des Sciences de l'agriculture et de l'alimentation, Centre de Recherche en Horticulture, Université Laval, Pavillon Paul-Comtois, Quebec, QC, Canada, G1V 0A6; Gerry Louis-Seize and Keith A. Seifert, Biodiversity (Mycology and Microbiology), Agriculture and Agri-Food Canada, Ottawa, ON, Canada K1A 0C6; and Richard R. Bélanger, Département de Phytologie, Faculté des Sciences de l'agriculture et de l'alimentation, Centre de Recherche en Horticulture, Université Laval, Quebec \begin{abstract}
record of pathogen to greenhouse tomato in Northeastern America. Plant Dis. 98:292-298.
Recently, a new disease was reported on greenhouse tomato plants in both Quebec, Canada and Maine, United States. Symptomatic plants bore brown lesions at graft points and pruning sites, resulting in expanding cankers with clearly delineated margins. Diseased plants eventually wilted and died within a few weeks following the appearance of the first symptoms. The symptoms are reminiscent of infection by Fusarium oxysporum f. sp. radicis-lycopersici, with the notable difference of a discoloration of the pith area rather than the vascular tissues. A homothallic Fusarium sp. was consistently recovered from these lesions. Sequencing of the internal transcribed spacer and the partial translation elongation factor $1-\alpha$ gene identified the species as
\end{abstract}

Abstract

Moine, L. M., Labbé, C., Louis-Seize, G., Seifert, K. A., and Bélanger, R. R. 2014. Identification and detection of Fusarium striatum as a new

F. striatum. Pathogenicity tests with $F$. striatum isolates from diseased tissues reproduced disease symptoms in tomato similar to those observed on tomato plants in the greenhouses. Specific detection of $F$. striatum from mycelia and diseased and disease-free plant tissues was achieved by developing a polymerase chain reaction-based test. These results establish, for the first time, that the species $F$. striatum is the cause of crown and stem rot affecting tomato in North America. In addition $F$. striatum was detected from all sampled tissues of plants delivered by the nursery common to both growers, suggesting that the transplants would be the source of the inoculum.
Greenhouse tomato (Solanum lycopersicum) is one of the most economically important vegetable crops of North America. However, the warm and humid environment and high plant density of greenhouse crops is conducive to the establishment and spread of fungal diseases such as gray mold, caused by the fungus Botrytis cinerea; powdery mildew, caused by Oidium neolycopersici; and Fusarium crown and root rot, caused by Fusarium oxysporum f. sp. radicislycopersici (16). Fortunately, the majority of these diseases can be controlled by optimal manipulation of environmental conditions, fungicides, or use of resistant varieties $(12,14,17,20)$. Nevertheless, when a new disease emerges, it becomes very difficult to find a control solution if the pathogen agent is not properly identified.

In 2006, a new disease was observed in commercial greenhouses located in Quebec, Canada and Maine, United States and no curative or preventive treatment successfully delayed its spread. Since its first appearance, the percentage of affected plants has steadily increased and reached $20 \%$ by 2012 .

Based on initial observations, F. oxysporum f. sp. radicis-lycopersici $(13,16)$ was believed to be the causal agent but the lack of discoloration of vascular tissues suggested that an unknown pathogen was responsible for the observed symptoms. Nevertheless, morphological observations of the putative pathogen revealed the presence of macroconidia and phialids typical of the $F$. solani species complex (FSSC) $(9,29,40)$.

Corresponding author: Richard R. Bélanger,

E-mail: richard.belanger@fsaa.ulaval.ca

Accepted for publication 26 September 2013.

http://dx.doi.org/10.1094/PDIS-08-13-0844-RE

(C) 2014 The American Phytopathological Society
Implementation of appropriate disease management and measures needed to prevent or control a disease requires a reliable identification and detection of the pathogen. Molecular biology techniques, especially those involving the polymerase chain reaction (PCR), have provided an alternative and sensitive approach for the detection and identification of plant pathogens and many soilborne pathogenic fungi $(26,35)$. Several regions, such as the internal transcribed spacer (ITS) region of the ribosomal DNA (rDNA) and, particularly, the translation elongation factor 1- $\alpha$ (tef) gene, are useful to identify and discriminate Fusarium spp. $(10,27,34)$.

Distinct species of the FSSC can be ubiquitous and saprophytic but some can also be pathogenic to specific plants, causing considerable economic impact mainly on horticultural plants $(5,18)$. In fact, some members of the FSSC, including F. solani f. sp. eumartii, were found to cause disease on tomato plants $(22,30)$, emphasizing the importance of accurate identification of the causal agent.

The objectives of the present study were to (i) isolate, identify, and evaluate the pathogenicity of fungal isolates recovered from diseased tomato tissues in two commercial greenhouses in Quebec and Maine; (ii) develop a species-specific PCR protocol to discriminate the causal agent from other related fungi in artificially and naturally contaminated samples of tomato plants, and (iii) find the source of the inoculum.

\section{Materials and Methods}

Plant sampling and DNA extraction. Diseased tomato plants were obtained from commercial greenhouses located in central Quebec and the northeastern United States. In total, 55 samples (50 from Quebec and 5 from Maine greenhouses) were collected, consisting of plants bearing typical cankers. Tissue sampling ( 5 by 10 to $20 \mathrm{~mm}$ ) was made from the margin of cankers with a sterile scalpel. The samples were immediately surface disinfected in 
$0.05 \% \mathrm{NaOCl}(3 \mathrm{~min})$ and $70 \%$ ethanol $(3 \mathrm{~min})$ and rinsed twice for $5 \mathrm{~min}$ in sterile distilled water. After drying on sterile absorbent paper, collected cleaned tissues were halved. One half was frozen at $-80^{\circ} \mathrm{C}$, then lyophilized and stored at $-15^{\circ} \mathrm{C}$ for further DNA extraction. The other part was sliced into small pieces and used for fungal isolation. Samples for control tests were obtained from stems of plants without disease symptoms. These samples were surface disinfected and stored as above.

In order to determine whether the transplants were carriers of inoculum, young tomato plants coming from the growers' common nursery were also sampled. Briefly, 2-cm pieces were sampled from the stems, graft points, above and under the graft points, and root tissues. Samples were frozen at $-80^{\circ} \mathrm{C}$, then lyophilized and stored at $-15^{\circ} \mathrm{C}$ for further DNA extraction.

Fungal strains and cultivation. Control strains. F. oxysporum, $F$. graminearum, $F$. sambucinum, and $F$. oxysporum f. sp. radicislycopersici were kindly provided by Dr. Russell Tweddell, Université Laval, Canada, and used as control strains. F. striatum strain 2880-2 was kindly provided by Mr. Gérard Gilbert from the Laboratoire de diagnostic en phytoprotection (MAPAQ, QC, Canada). All cultures were grown on synthetic low nutrient agar (SNA; 25) at $24^{\circ} \mathrm{C}$ for 5 days and stored at $4^{\circ} \mathrm{C}$ for the duration of the experiment.

Fungal isolates. Surface-sterilized pieces (see above) from diseased tomato plants were immediately plated on petri dishes filled with potato dextrose agar (PDA) amended with antibiotics (chloramphenicol at $80 \mathrm{mg} /$ liter and streptomycin sulfate at $80 \mathrm{mg} / \mathrm{liter}$ ). The plates were then incubated for 4 to 5 days at $28^{\circ} \mathrm{C}$. Colonies were exposed under near-UV light and examined after $72 \mathrm{~h}$. In addition, the isolates were maintained on SNA at $4^{\circ} \mathrm{C}$.

Two representative isolates were deposited in the Canadian Collection of Fungal Cultures as DAOM 242301 and 242302 (AAFC, Ottawa).

DNA extraction. Fungal DNA. A minimal liquid culture medium was suitable to obtain a high titer of microconidia during cultivation of Fusarium strains, and this material was used for DNA extraction. Briefly, 1-cm mycelial plugs were collected from the edge of actively growing colonies. For each isolate, five pieces of mycelium were transferred into a 250-ml Erlenmeyer flask containing $50 \mathrm{ml}$ of the following medium: $\left(\mathrm{NH}_{4}\right)_{2} \mathrm{SO}_{4}, 1 \mathrm{~g} / \mathrm{liter}$; $\mathrm{KH}_{2} \mathrm{PO}_{4}, 1 \mathrm{~g} / \mathrm{liter} ; \mathrm{MgSO}_{4} \cdot 7 \mathrm{H}_{2} \mathrm{O}, 0.5 \mathrm{~g} /$ liter; and $\mathrm{FeSO}_{4} \cdot 7 \mathrm{H}_{2} \mathrm{O}$, $0.01 \mathrm{~g} /$ liter; in $50 \mathrm{mM}$ citrate buffer (sodium citrate dihydrate $12.85 \mathrm{~g} /$ liter; citric acid $1.21 \mathrm{~g} / \mathrm{liter}$ ), amended with dextrose at 10 $\mathrm{g} /$ liter and yeast extract BACTO (BD and Co.) at $3 \mathrm{~g} / \mathrm{liter}$. All salts were of technical grade. Cultures were grown for 4 days at room temperature on a rotary shaker set at $150 \mathrm{rpm}$.

For total DNA extraction, 2-ml aliquots of conidia were harvested by centrifugation $(5,000 \times g$ for $10 \mathrm{~min})$. The fungal cell pellets were extracted using the EZNA Plant DNA Kit (OMEGA bio-tek), according to the manufacturer's instructions. DNA concentration was determined with a spectrophotometer (NanoView; GE Healthcare) and the final DNA concentration was adjusted to $50 \mathrm{ng} / \mu \mathrm{l}$ in sterile water for further use in PCR reactions. DNA extracts were kept at $-15^{\circ} \mathrm{C}$ for storage.

Plant DNA. All plant samples were pulverized with a bead mill TissueLyser (Qiagen) as follows: $3 \mathrm{~min}$ at $30 \mathrm{~Hz}$ with 3 -mm beads
(35). The genomic DNA was extracted from 50-mg aliquots using the EZNA Plant DNA Kit (OMEGA bio-tek), following the manufacturer's instructions. Plant DNA was diluted to $50 \mathrm{ng} / \mu \mathrm{l}$ in sterile water for use in PCR reactions.

PCR reactions. Primers. The markers used for the identification of fungi were the ITS region of rDNA and the tef gene. The ITS region was amplified with two sets of primers. The first combination, ITS1F (8) and ITS4 (37), was specific to fungal ITS. The second set, ITS-Fu-f/ITS-Fu-r, was specific to Fusarium spp. (1). The tef region amplification was performed with universal primers EF1 and EF2 (29). The second tef primer set, TEF-Fs4f and TEF-Fs4r (4), was used to discriminate the Fusarium sp. isolated from infected tomato from the other Fusarium spp., with the exception that the primer TEF-Fs4r was slightly modified (final "C" removed) to match perfectly with our own tef sequence. Full sequences for the primers and PCR conditions are provided at Table 1.

PCR amplification. DNA amplification was performed in $20 \mu \mathrm{l}$ of mixture that contained $0.2 \mathrm{mM}$ dNTP (Life Technologies), 0.8 $\mu \mathrm{M}$ each primer (Life Technologies), $0.1 \mathrm{U}$ of Taq DNA Polymerase (New England Biolabs), $1 \times$ of TAQ buffer given with the enzyme, and $1 \mu \mathrm{l}$ of genomic DNA $(50 \mathrm{ng} / \mu \mathrm{l})$. For reactions involving DNA extracted from the plant tissues, $5 \%$ dimethyl sulfoxide was added in the PCR mixture; $20-\mu l$ volumes were completed with sterile water. Negative controls that excluded the DNA template were included in every experiment. Amplification was carried out with a thermal cycler (Mastercycler; Eppendorf), programmed differently for each primer set (Table 1). PCR products were analyzed on $0.8 \%$ agarose gel in tri-boric acid EDTA buffer at $120 \mathrm{~V}$ for $35 \mathrm{~min}$. Agarose gels were stained with ethidium bromide and photographed under UV light.

Cloning and sequencing. The ITS and tef PCR products, generated using the primer pairs ITS1F/ITS4, EF1/EF2, and TEFFs4f/TEF-Fs4r, were purified using the EZNA Cycle-Pure kit, (OMEGA bio-tek). The PCR products were cloned using the pGEM-T Easy Vector System I (Promega), according to the manufacturers' instructions. Escherichia coli TOP 10 chemically competent cells were used to amplify the transformed plasmids. Plasmid DNA from white colonies was purified by kit (EZNA Plasmid Mini kit I; OMEGA bio-tek) and analyzed on agarose gels. Positive clones were sent to sequencing at Plate-Forme génomique du CHUL (Université Laval, www.sequences.crchul.ulaval.ca). Sequencing was performed using the M13 sequencing primer-binding sites.

Pathogenicity tests. Culture conditions. Seed from three cultivars ('Trust', 'Yellow', and 'Multifort') were sown individually in $15-\mathrm{cm}$ pots containing pasteurized Promix (Premier Tech). Tomato plants were grown in greenhouse for 5 weeks at 25 and $20^{\circ} \mathrm{C}$ with $70 \%$ relative humidity $(\mathrm{RH})$ and a 14 -h photoperiod prior to inoculation. Plants were watered daily and fertilized weekly (20-20-20; $6 \mathrm{mg} / \mathrm{liter}$ of water).

Pathogen inoculation. Seven isolates previously purified from diseased tomato tissues, including three isolates from Quebec, two from Maine, and two isolates of F. oxysporum, were tested for their pathogenicity. The seven isolates were grown on PDA for 8 days at $28^{\circ} \mathrm{C}$ to yield a good microconidia titer. One-centimeter incisions

Table 1. Sequences of primer sets derived from the internal transcribed spacer (ITS) region and the translation elongation factor (TEF) 1- $\alpha$

\begin{tabular}{|c|c|c|c|c|c|}
\hline $\begin{array}{l}\text { Primer } \\
\text { code }\end{array}$ & Sequence $\left(5^{\prime}-3^{\prime}\right)$ & Target & $\begin{array}{l}\text { Expected size of } \\
\text { fragments (bp) }\end{array}$ & Specificity & PCR conditions ${ }^{\mathbf{a}}$ \\
\hline ITS1F & CTTGGTCATTTAGAGGAAGTAA & ITS & $\approx 605$ & Fungi & 30 cycles; $30 \mathrm{~s}$ at $94^{\circ} \mathrm{C}, 1 \mathrm{~min}$ at $59^{\circ} \mathrm{C}, 1 \mathrm{~min}$ at $72^{\circ} \mathrm{C}$ \\
\hline ITS4 & TCCTCCGCTTATTGATATGC & & & & \\
\hline ITS-Fu-f & CAACTCCCAAACCCCTGTGA & ITS & $\approx 400$ & Fusarium spp. & 35 cycles; $30 \mathrm{~s}$ at $94^{\circ} \mathrm{C}, 30 \mathrm{~s}$ at $59^{\circ} \mathrm{C}, 30 \mathrm{~s}$ at $72^{\circ} \mathrm{C}$ \\
\hline ITS-Fu-r & GCGACGATTACCAGTAACGA & & & & \\
\hline EF1 & ATGGGTAAGGARGACAAGAC & tef & $\approx 733$ & Fungi & 30 cycles; $30 \mathrm{~s}$ at $94^{\circ} \mathrm{C}, 30 \mathrm{~s}$ at $60^{\circ} \mathrm{C}, 1.5 \mathrm{~min}$ at $72^{\circ} \mathrm{C}$ \\
\hline EF2 & GGARGTACCAGTSATCATGTT & & & & \\
\hline TEF-Fs4f & ATCGGCCACGTCGACTCT & tef & 650 & F. solani/F. striatum & 35 cycles; $30 \mathrm{~s}$ at $94^{\circ} \mathrm{C}, 30 \mathrm{~s}$ at $59^{\circ} \mathrm{C}, 30 \mathrm{~s}$ at $72^{\circ} \mathrm{C}$ \\
\hline TEF-Fs $4 r^{b}$ & GGCGTCTGTTGATTGTTAG & & & & \\
\hline
\end{tabular}


were made on the plant stems, just under the petiole of the middle leaf, with a sterile scalpel. The inoculum was collected by scraping the surface of a fungal colony with a sterile scalpel. The inoculum was then inserted into the incision. Control plants were inoculated with sterile PDA. The inoculated areas were protected with strips of aluminum foil. Each isolate was tested on all cultivars in three replicates. Tomato plants were transferred to a growth chamber at 25 and $20^{\circ} \mathrm{C}$ with $80 \% \mathrm{RH}$ and a 16 -h photoperiod and observed daily for disease progression. Fungal colonies isolated from stem cankers as well as collected necrotic plant tissues surrounding cankers were submitted to PCR analysis to confirm the identity of the pathogen.
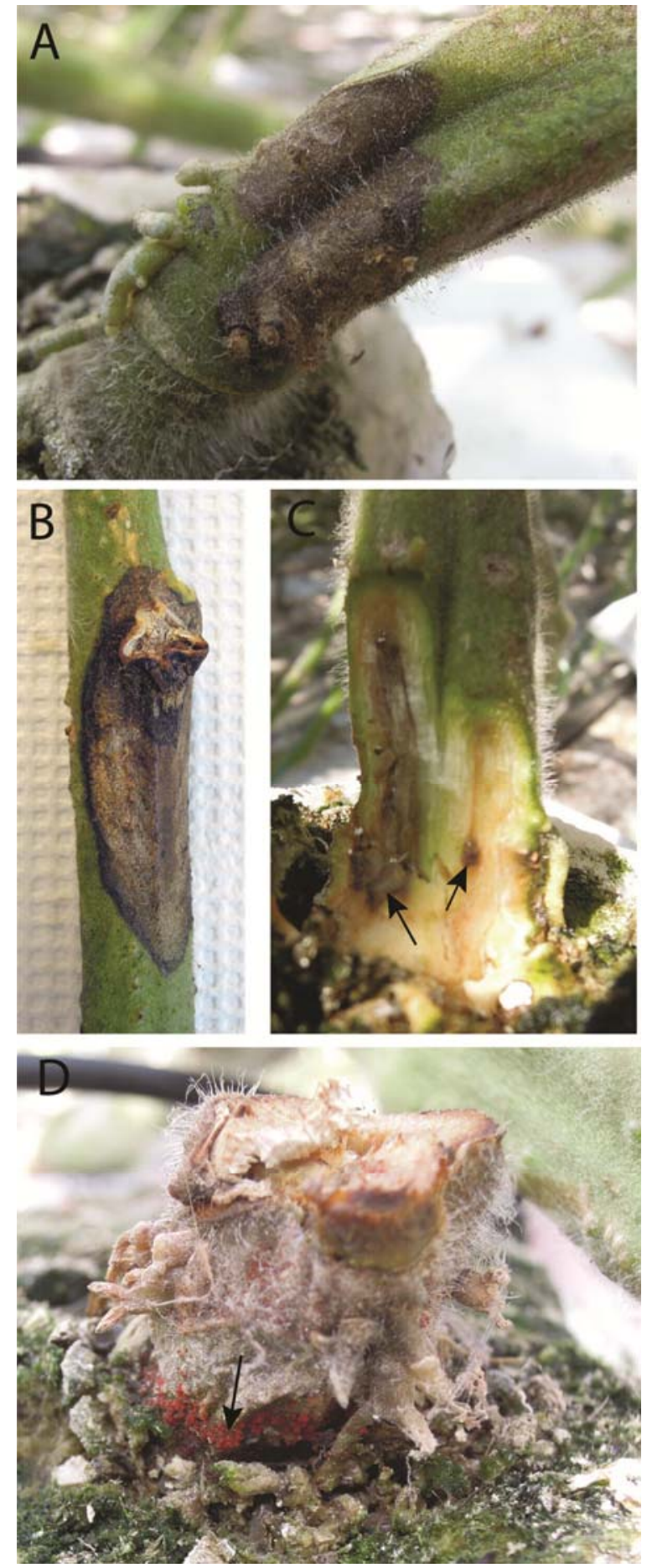

Fig. 1. Photographs of diseased tomato plants. A, Brown canker at graft point; $\mathbf{B}$, brown canker at site of a pruning lesion; $\mathbf{C}$, dark-brown discoloration of the pith area; $\mathbf{D}$, orange-red to dark-red perithecia at the base of a diseased tomato plant.

\section{Results}

Disease symptoms. Tomato plants dying from unspecified causes were reported from commercial greenhouse operations in central Quebec and the northeastern United States. Symptomatic plants had brown cankers at graft points (Fig. 1A) and at sites of pruning lesions (Fig. 1B). The cankers were flat and depressed, with a clear delineation from the stem. A longitudinal section of the stems showed a dark brown discoloration of the pith area while the vascular tissues were seemingly untouched (Fig. 1C). Orangered to dark-red perithecia were observed on necrotic tissues and directly on rockwool slabs (Fig. 1D). Diseased tomato plants died in less than 2 months if the cankered area was not removed within 2 weeks following the observation of the first symptoms.

Collection sample and fungal description. From the $55 \mathrm{sam}-$ ples collected and received, 53 isolates were recovered from the cankers collected in Quebec and 5 from the United States. Surface disinfection and fragmentation of the diseased tissues in small pieces before plating allowed the consistent isolation of one fungus with uniform morphology in culture, producing cottony, cream to yellowish colonies on PDA (group 1; Fig. 2A and B). In fact, only three isolates collected in Quebec presented a different morphology in culture and developed salmon-colored colonies (group 2; data not shown). Microscopic observations revealed that all isolates formed conidiophores, microconidia, and macroconidia typical of the genus Fusarium (Fig. 2C and D).

Perithecia were formed by all cultures of group 1 isolates on SNA under UV whereas single-spore cultures recovered from group 2 isolates did not form perithecia. The morphology of perithecia and ascospores (Fig. 2E and F) was similar and compatible with descriptions of the Haematonectria sexual states of the FSCC (31). Ascospores (eight per ascus) were arranged within cylindrical asci.

Fungal identification. PCR genetic analysis was performed on seven randomly selected isolates, five from group 1 (08A, 12A, 23A, 24A, and 45A) and two from group 2 (14A and 19A). Using fungi-specific primers ITS1F and ITS4, 605-bp amplicons were generated, cloned, and sequenced. Comparison of the sequencing results with GenBank indicated that the 605-bp fragment amplified from group 1 isolates was $99 \%$ identical to $F$. striatum (accession number AF178398) (26) while a fragment from group 2 had 100\% homology with $F$. oxysporum (accession EU839403).

A second PCR analysis was performed using fungi-specific tef primers EF1/EF2. A 733-bp amplicon was obtained for the seven strains. Sequences of group 1 yielded a $99.9 \%$ homology with the tef sequence of $F$. striatum NRRL 52699 (accession number JF740782) (28) and with F. striatum MAFF237668 (GenBank accession AB513844), isolated from tomato in Japan (22). The same isolates had $98 \%$ homology with $F$. solani f. sp. eumartii recovered from Japan and California (AB498980 and DQ164848, respectively; 22). Sequencing of the tef region of the two isolates from group 2 confirmed their belonging to $F$. oxysporum species (accession number JF794779).

The sequences obtained from group 1 isolates have been deposited in the National Center for Biotechnology Information (NCBI) GenBank as KF483867 (23A), KF483868 (24A), KF483869 (08A), KF483870 (12A), and KF483871 (45A).

Pathogenicity tests. Inoculation of healthy tomato plants with the group 1 randomly selected isolates identified previously as $F$. striatum resulted in lesions identical to those observed in diseased plants (Fig. 3B and C). Indeed, a typical brown discoloration of the stem was visible within 2 to 3 days on all inoculated plants. After 1 week, wilting symptoms were observed as cankers expanded from the inoculation point. A longitudinal section of the stems of diseased plants revealed dark-brown pith with no apparent coloration of the vascular tissues (Fig. 3C), matching the symptoms originally observed on greenhouse plants (Fig. 1C). Tissue sampling at the margins of advancing cankers yielded fungal isolates that were re-identified as $F$. striatum by sequencing of the tef region, thus completing Koch's postulates. 
The isolates identified as $F$. oxysporum from our initial sampling were nonpathogenic on tomato plants (Fig. 3D) and control plants were symptomless (Fig. 3A).

Although all three cultivars developed cankers following inoculation with isolates of $F$. striatum, they did not respond with the same intensity. In fact, lesion spread on Yellow was systematically longer than on Trust or Multifort (Fig. 3E-G).

Specificity of PCR amplification. Primer specificity on purified fungal genomic DNA. Using the Fusarium spp.-specific primers (ITS-Fu-f/ITS-Fu-r), PCR products were generated from all the pure cultures of Fusarium isolates studied, including $F$. oxysporum f. sp. radicis-lycopersici, $F$. oxysporum, $F$. sambucinum, and $F$. graminearum (Fig. 4A). However, when specifically optimized primers TEF-Fs4f/TEF-Fs4r (Table 1) were used, only Fusarium strains isolated from diseased tomato plants displayed a single and uniform amplification product of 650 bp (Fig. 4B). Subsequent analysis of the five isolates from group 1 and the two isolates from group 2 used for pathogenicity tests confirmed the specificity of the primers toward F. striatum (Fig. 5). As a matter of fact, all 55 isolates from group 1 gave single amplification products using the primers TEF-Fs4f and TEF-Fs4r whereas no amplification occurred when these specific primers were tested on the three isolates of group 2 (results not shown).

Detection directly from plant tissue DNA. A 650-bp PCR product was amplified following the DNA extraction of diseased plant tissues of the 55 cankers (Fig. 6). No DNA fragment was amplified from control plants (Fig 6). PCR amplification was performed twice for each DNA extract with similar results.

Source of $\boldsymbol{F}$. striatum. All samples of stems, graft points, above and under the graft points, and roots from nursery-plants tissues gave a single PCR product of about $400 \mathrm{bp}$ using primers ITS-Fuf/ITS-Fu-r (data not shown) and $650 \mathrm{bp}$ using primers TEFFs4f/TEF-Fs4r (Table 2).

The tef DNA sequences of two randomly selected samples (LMA61 and LMA75) were 100\% identical to those of F. striatum isolated from cankers, confirming that the PCR products amplified with TEF-Fs4f/TEF-Fs4r were from $F$. striatum (Table 2). Sequences from those two isolates were deposited in the NCBI GenBank as KF483872 (LMA61) and KF483873 (LMA75).

\section{Discussion}

This study highlighted the presence of $F$. striatum as the causal agent of crown and stem rot and wilt of greenhouse tomato plants in North America. We were further able to develop a PCR-based test by optimizing a tef primer set suggested by Arif (4) that allowed the fast detection of $F$. striatum.

Although Fusarium spp. are significant plant pathogens affecting a large variety of hosts, their identification at the species level remains complex $(2,10,18)$. Accurate identification of this new tomato pathogen represented a unique challenge because of the prevalence of Fusarium spp. attacking tomato plants $(19,22,36,39)$ and the taxonomic complexity related to FSSC (40). By morpho-
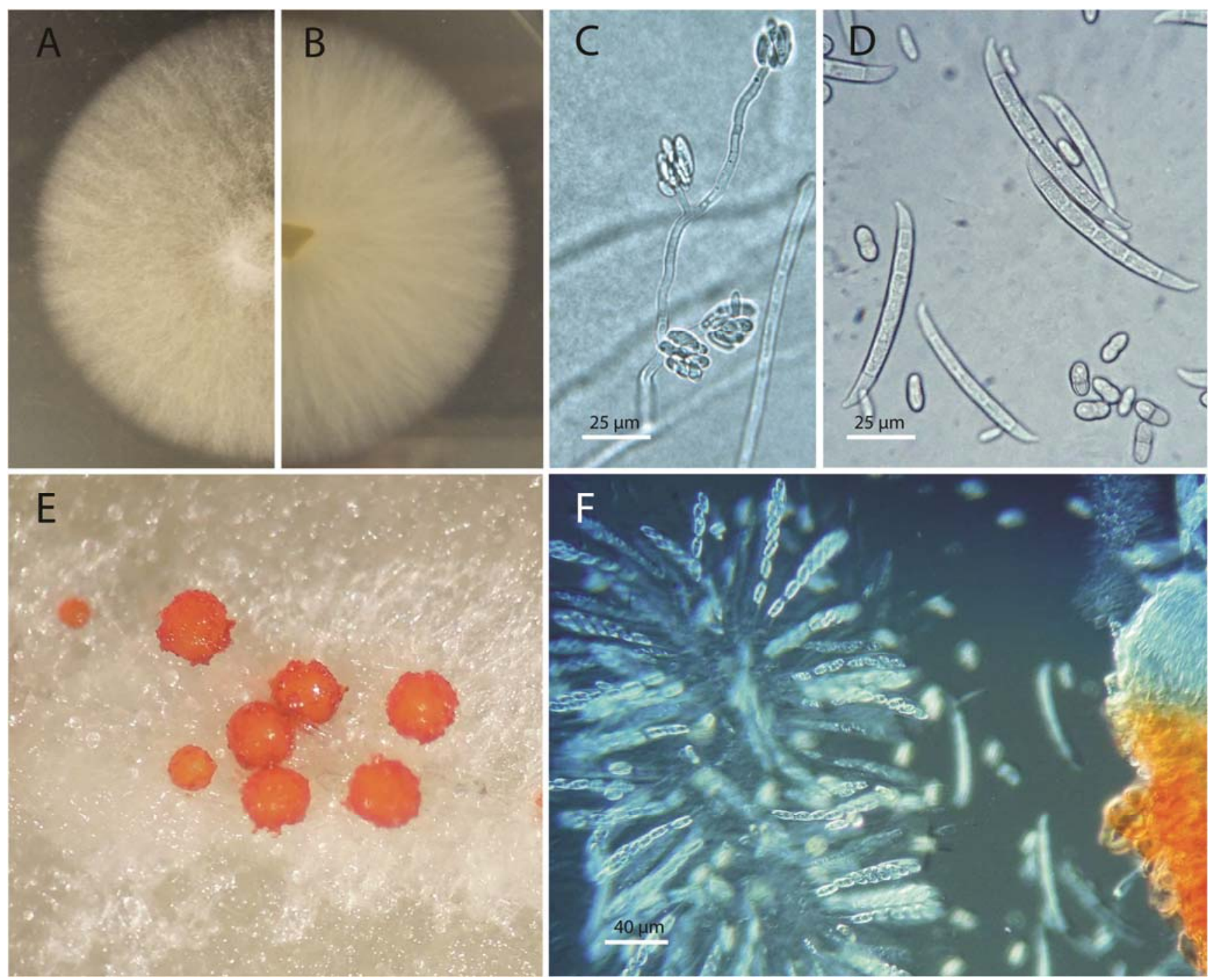

Fig. 2. Photographs and light micrographs of sexual and asexual structures of fungal isolates from diseased tomato plants. A, Top view of a typical colony growing on potato dextrose agar; B, bottom view; C, phialids; D, microconidia and macroconidia; E, perithecia identified as typical of Fusarium striatum produced from a single-spore culture on SNA medium; $\mathbf{F}$, ascospores contained within asci, obtained from perithecia of $F$. striatum. 
logical observations, the disease agent was initially identified as $F$. solani. In the taxonomic system of Nelson et al. (23), F. solani was considered a single morphologically defined species, although the occurrence of host-specific formae speciales and seven distinct mating populations was long recognized (21). Since then, many phylogenetic species have been described, including several species of $F$. solani responsible for the sudden death of soybean plants (3). Subsequent multigene analyses revealed the existence of over 60 phylogenetic species within the FSSC, divided into three large clades $(7,9)$.

Some species of the FSSC are morphologically distinct but, in general, they are most easily recognized by specific pathogenicity combined with diagnostic DNA barcodes, generally partial sequences of tef $(10,15)$. The general fungal barcode for fungi, the ITS (32), is often not diagnostic to the species level in the genus Fusarium but is sometimes informative. The tef sequences of our five strains isolated from diseased tissues had 99.9\% homology with MAFF237668, identified as F. striatum (GenBank accession AB513844) and isolated from tomato plants in Japan (22). Analysis of the ITS region led to the same identification. As with the strain from Japan, our strains were homothallic, producing perithecia on SNA. Moreover, our morphological observations were consistent with those of Sherbakoff (33) and Rossman et al. (31).

F. striatum was described by Sherbakoff (33) from potato tubers collected in Colorado; it caused a "striate rot" when inoculated into potato. Wollenweber and Reinking (38) considered Sherbakoff's species a variety of $F$. solani, and it was subsequently subsumed completely into the broad morphological concept of that species until Nirenberg and Breilmaier-Liebetanz (24) associated it with a sexual state, then called Haematonectria ipomoeae (31).
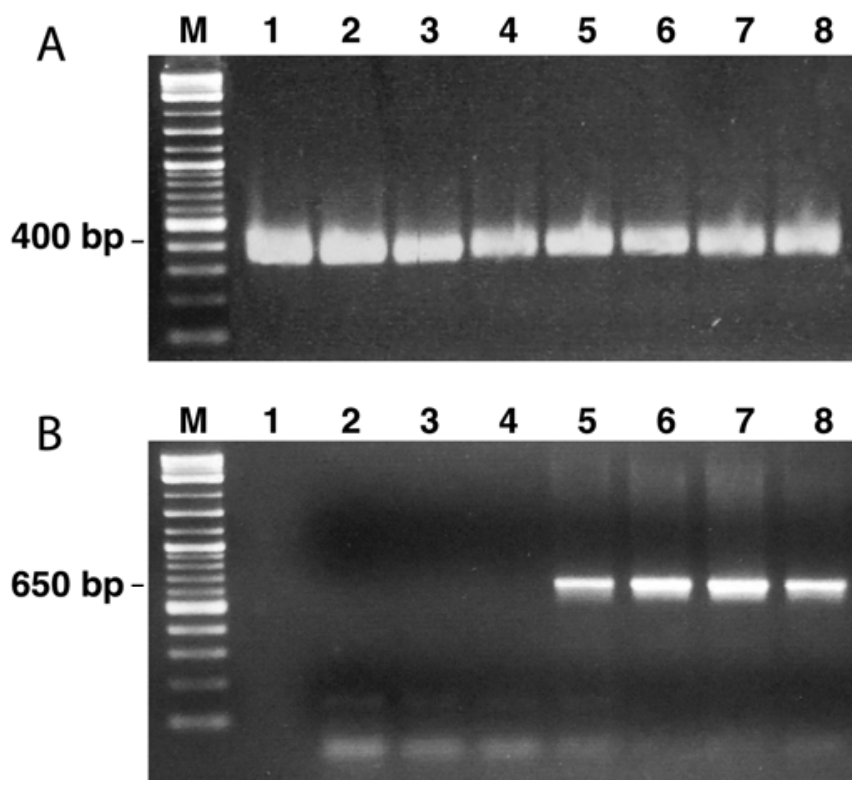

Fig. 4. Gel electrophoresis of polymerase chain reaction-amplified products (A, primers ITS-Fu-f/ITS-Fu-r and B, primers TEF-Fs4f/TEF-Fs4r) from the following strains: lane 1, Fusarium oxysporum f. sp. radicis-lycopersici; lane 2, F. oxysporum spp.; lane 3, F. graminearum; lane 4, F. sambucinum; lanes 5-8, group 1 isolates from diseased tomato plants.

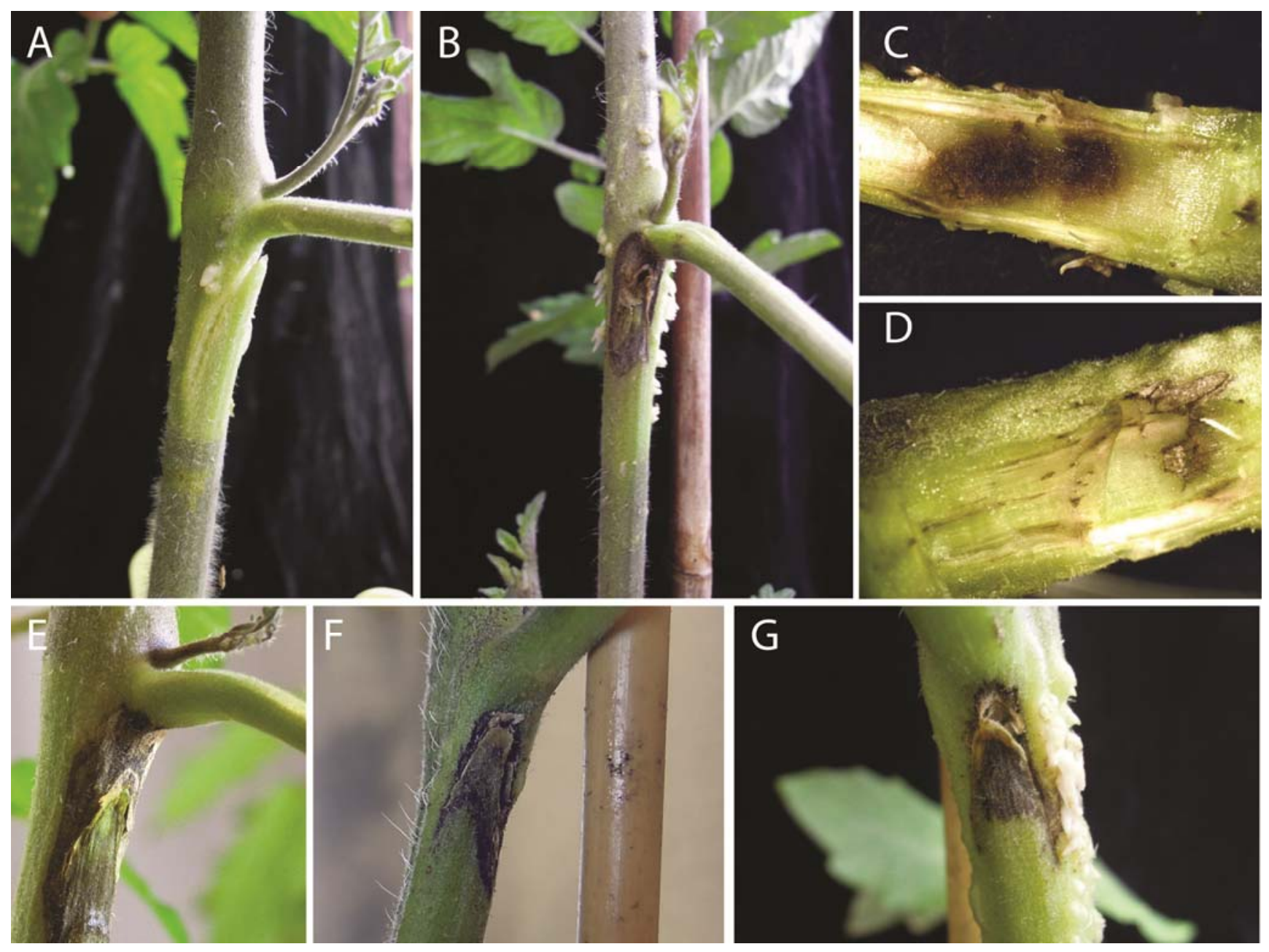

Fig. 3. Koch postulates. A, Control plant inoculated with agar medium; B, canker on a plant inoculated with group 1 isolates (Fusarium striatum); C, longitudinal section of the canker obtained in B; D, longitudinal section of a plant inoculated with group 2 isolates ( $F$. oxysporum). Lesion development on plants from E, 'Yellow'; $F$, 'Multifort'; and $\mathbf{G}$, 'Trust' following inoculation with $F$. striatum. Photographs were taken 8 days after inoculation. 
F. striatum was systematically isolated from the samples collected in central Quebec and Maine and pathogenicity tests of all selected isolates were positive. By contrast, the F. oxysporum isolates that were also obtained from a few cankers yielded negative results when assayed against tomato. Because $F$. striatum was reisolated from the plant tissues and re-identified, pathogenicity was irrefutably established according to Koch's postulates. Interestingly, symptoms caused by $F$. solani $\mathrm{f}$. sp. eumartii, recently described as the agent of foot rot in tomato plants in Japan, were very similar to those observed with $F$. striatum and a high homology (>98\%) was found between their tef sequences. A distinguishing feature appears to be the heterothallism of $F$. solani f. sp. eumartii in contrast to the homothallism of F. striatum (22).

The tef region is an attractive marker enabling one to choose species-specific primers to detect and discriminate the pathogen,

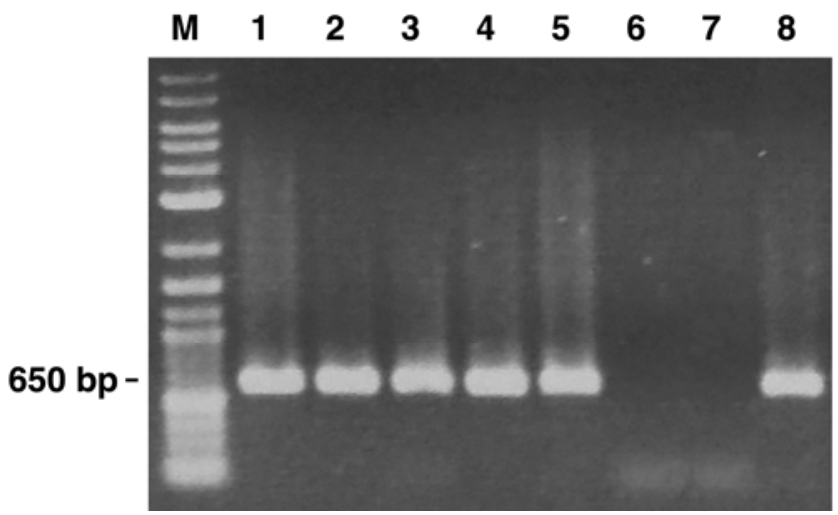

Fig. 5. Polymerase chain reaction amplification using the primers TEF-fs $4 f$ and TEF-Fs4r on DNA extracted from cultures of isolates tested for their pathogenicity. Lanes 1-5, five Fusarium striatum isolates used in pathogenicity tests (08A, 12A, 23A, 24A, and 45A); lanes 6 and 7, F. oxysporum isolates; lane 8, F. striatum control, strain 2820-2 (from MAPAQ).

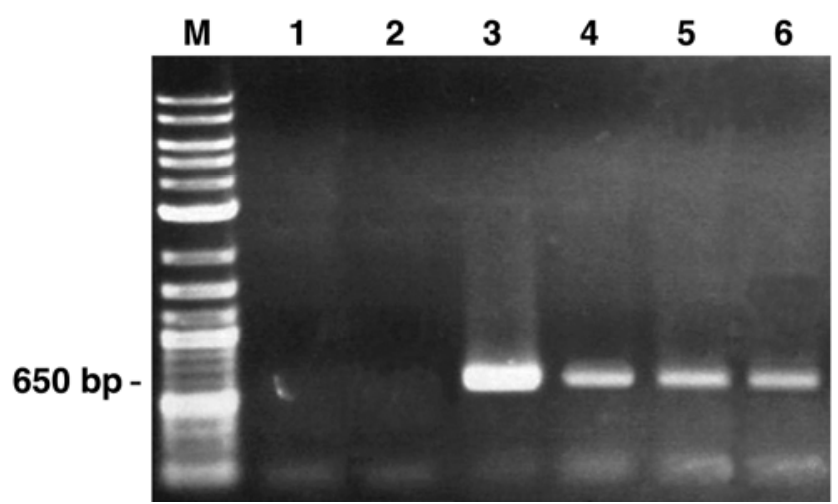

Fig. 6. Detection of Fusarium striatum in plant DNA extracts using the set of primers TEF-fs $4 f$ and TEF-Fs4r. Lane 1, DNA from a healthy plant (negative control 1); lane 2, purified mycelium of $F$. oxysporum isolate (negative control 2); lane 3 , purified mycelium of $F$. striatum isolate (positive control); lanes 4-6, tissues from three randomly selected cankers.

Table 2. Detection of Fusarium striatum in different parts of tomato plant received from the nursery with the set of primers TEF-Fs4f/TEF-Fs4r

\begin{tabular}{llc}
\hline Sample category & Tissue samples & $\begin{array}{c}\text { Positive PCR } \\
\text { amplification }^{\mathbf{a}}\end{array}$ \\
\hline Plants from the nursery & Stem & $6 / 6$ \\
& Graft point & $6 / 6$ \\
& Above graft point & $6 / 6$ \\
& Under graft point & $6 / 6$ \\
Control plant & Roots & $6 / 6$ \\
\hline
\end{tabular}

${ }^{a} \mathrm{PCR}=$ polymerase chain reaction . because variability occurs among sequences of closely related Fusarium spp. $(10,22)$. Indeed, detection of $F$. striatum using the specific primers TEF-fs $4 \mathrm{f}$ and TEF-Fs4r was positive for all plants expressing symptoms. As expected, these primers did not amplify $F$. oxysporum isolated from tomato plants or $F$. oxysporum f. sp. radicis-lycopersici, which causes similar wilt-like symptom. As Henson and French (11) demonstrated, the PCR-based detection technique is rapid, reliable, and accurate because the causal agent can be immediately detected in mixed samples that contain other morphologically similar fungi. However, in silico comparisons of the primer sequences against GenBank show that our assay does not distinguish among many of the component species of the FSSC, restricting its utility for screening, for example, soil or potting mixtures where other members of this species complex can be expected to occur. Under such cases, sequencing of the amplicons would be necessary for discrimination.

Based on our results combining the PCR assay with sequencing of the amplicons, we confirmed the presence of $F$. striatum in plant samples with no disease symptoms. These plants were obtained from the nursery supplying the greenhouse growers in Quebec as well as in Maine. This suggests that the inoculum was brought in by the nursery plants, given that $F$. striatum was recovered from all tissues sampled. As a first prophylactic measure, the PCR assay provides a preventive approach alerting the nursery and greenhouse growers to make sure that the plants are exempt from contamination when entering the greenhouse.

Another fortuitous observation regarding cultivar susceptibility to the disease could be exploited as a control method $(6,14,41)$. Although our objective was to test the pathogenicity of $F$. striatum, we noted that the pathogen did not develop as rapidly in Multifort and Trust as in Yellow. These observations indicate that genotypic differences exist among these cultivars; therefore, further investigations might enable the development of cultivars with a higher resistance to $F$. striatum.

In conclusion, we report the presence of $F$. striatum as the causal agent of crown and stem rot of greenhouse tomato in both Canada and United States. Moreover, we have shown that the PCR-based technique developed is a valuable tool for the rapid detection of this new tomato pathogen. At this stage, screening of nursery plants entering the greenhouse for the presence of $F$. striatum is considered the most sensible method to prevent spread of the disease.

\section{Acknowledgments}

This research was supported by the Innovative Agri-Food Sector Support Program offered by the province of Quebec and the grant from the Canada Research Chairs Program to R. R. Bélanger. We thank A. Boulianne and "Les Serres du St-Laurent Inc." staff for essential contribution toward obtaining the collection of tomato crown and stem rot samples from Quebec; and N. Shallow and Gérard Gilbert from the Laboratoire de diagnostic, MAPAQ, for helpful discussions.

\section{Literature Cited}

1. Abd-Elsalam, K. A., Aly, I. N., Abdel-Satar, M. A., Khalil, M. S., and Verreet, J. A. 2003. PCR identification of Fusarium genus based on nuclear ribosomal-DNA sequence data. Afr. J. Biotechnol. 2:82-85.

2. Aoki, T., O'Donnell, K., Homma, Y., and Lattanzi, A. R. 2003. Suddendeath syndrome of soybean is caused by two morphologically and phylogenetically distinct species within the Fusarium solani species complex-F. virguliforme in North America and F. tucumaniae in South America. Mycologia 95:660-684

3. Aoki, T., O’Donnell, K., and Scandiani, M. M. 2005. Sudden death syndrome of soybean in South America is caused by four species of Fusarium: Fusarium brasiliense sp. nov., F. cuneirostrum sp. nov., F. tucumaniae, and F. virguliforme. Mycoscience 46:162-183.

4. Arif, M., Chawla, S., Zaidi, N. W., Rayar, J. K., Variar, M., and Singh, U. S 2012. Development of specific primers for genus Fusarium and F. solani using rDNA sub-unit and transcription elongation factor (TEF-1 $\alpha$ ) gene. Afr. J. Biotechnol. 11:444-447.

5. Booth, C. 1971. The Genus Fusarium. Commonwealth Mycological Institute, Kew, UK

6. Bournival, B. L., Scott, J. W., and Vallejos, C. E. 1989. An isozyme marker for resistance to race 3 of Fusarium oxysporum $\mathrm{f}$. sp. lycopersici in tomato. Theor. Appl. Genet. 78:489-494.

7. Coleman, J. J., Rounsley, S. D., Rodriguez-Carres, M., Kuo, A., Wasmann, C. C., Grimwood, J., Schmutz, J., Taga, M., White, G. J., Zhou, S. G. 
Schwartz, D. C., Freitag, M., Ma, L. J., Danchin, E. G. J., Henrissat, B., Coutinho, P. M., Nelson, D. R., Straney, D., Napoli, C. A., Barker, B. M., Gribskov, M., Rep, M., Kroken, S., Molnár, I., Rensing, C., Kennell, J. C., Zamora, J., Farman, M. L., Selker, E. U., Salamov, A., Shapiro, H., Pangilinan, J., Lindquist, E., Lamers, C., Grigoriev, I. V., Geiser, D. M., Covert, S. F., Temporini, E., and VanEtten, H. D. 2009. The genome of Nectria haematococca: contribution of supernumerary chromosomes to gene expansion. PLoS Genet. 5:e1000618.

8. Gardes, M., and Bruns, T. D. 1993. ITS primers with enhanced specificity for basidiomycetes - application to the identification of mycorrhizae and rusts. Mol. Ecol. 2:113-118.

9. Geiser, D. M., Aoki, T., Bacon, C. W., Baker, S. E., Bhattacharyya, M. K., Brandt, M. E., Brown, D. W., Burgess, L. W., Chulze, S., Coleman, J. J., Correll, J. C., Covert, S. F., Crous, P. W., Cuomo, C. A., De Hoog, G. S., Di Pietro, A., Elmer, W. H., Epstein, L., Frandsen, R. J. N., Freeman, S., Gagkaeva, T., Glenn, A. E., Gordon, T. R., Gregory, N. F., HammondKosack, K. E., Hanson, L. E., del Mar Jiménez-Gasco, M., Kang, S., Kistler, H. C., Kuldau, G. A., Leslie, J. F., Logrieco, A., Lu, G., Lysøe, E., Ma, L.-J., McCormick, S. P., Migheli, Q., Moretti, A., Munaut, F., O’Donnell, K., Pfenning, L., Ploetz, R. C., Proctor, R. H., Rehner, S. A., Robert, V. A. R. G., Rooney, A. P., bin Salleh, B., Scandia, M. M., Scauflaire, J., Short, D. P. G., Steenkamp, E., Suga, H., Summerell, B. A., Sutton, D. A., Thrane, U., Trail, F., Van Diepeningen, A., VanEtten, H. D., Viljoen, A., Waalwijk, C., Ward, T. J., Wingfield, M. J., Xu, J.-R., Yang, X.-B., Yli-Mattila, T., and Zhang, N. 2013. Letter to the editor: one fungus, one name: defining the genus Fusarium in a scientifically robust way that preserves longstanding use. Phytopathology 103:400-408.

10. Geiser, D. M., Jimenez-Gasco, M. M., Kang S., Makalowska, I., Veeraraghavan, N., Ward, T. J., Zhang, N., Kuldau, G. A., and O'Donnell, K. 2004. FUSARIUM-ID v. 1.0: a DNA sequence database for identifying Fusarium. Eur. J. Plant Pathol. 110:473-479.

11. Henson, J. M., and French, R. C. 1993. The polymerase chain reaction and plant disease diagnosis. Annu. Rev. Phytopathol. 31:81-109.

12. Jarvis, W. R. 1989. Managing diseases in greenhouse crops. Plant Dis. 73:190-194.

13. Jones, J. B., Jones, J. P., Stall, R. E., and Zitter, T. A. 1991. Compendium of Tomato Diseases. American Phytopathological Society, St. Paul, MN

14. King, S. R., Davis, A. R., Zhang, X., and Crosby, K. 2010. Genetics, breeding and selection of rootstocks for Solanaceae and Cucurbitaceae. Sci. Hortic. 127:106-111.

15. Kristensen, R., Torp, M., Kosiak, B., and Holst-Jensen, A. 2005. Phylogeny and toxigenic potential is correlated in Fusarium species as revealed by partial translation elongation factor 1 alpha gene sequences. Mycol. Res. 109:173-186

16. Lagopodi, A. L., Ram, A. F., Lamers, G. E., Punt, P. J., Van den Hondel, C. A., Lugtenberg, B. J., and Bloemberg, G. V. 2002. Novel aspects of tomato root colonization and infection by Fusarium oxysporum f. sp. radicis-lycopersici revealed by confocal laser scanning microscopic analysis using the green fluorescent protein as a marker. Mol. Plant-Microbe Interact. 15:172-179.

17. Lee, J. M., Kubota, C., Tsao, S. J., Bie, Z., Echevarria, P. H., Morra, L., and Oda, M. 2010. Current status of vegetable grafting: diffusion, grafting techniques, automation. Sci. Hortic. 127:93-105.

18. Leslie, J. F., and Summerell, B. A. 2006. The Fusarium Laboratory Manual. Blackwell Publishing, Ames, IA.

19. Marlatt, M. L., Correll, J. C., Kaufmann, P., and Cooper, P. E. 1996. Two genetically distinct populations of Fusarium oxysporum f. sp. lycopersici race 3 in the United States. Plant Dis. 80:1336-1342.

20. Marois, J. J., and Mitchell, D. J. 1981. Effects of fumigation and fungal antagonists on the relationships of inoculum density to infection incidence and disease severity in Fusarium crown rot of tomato. Phytopathology 71:167-170.

21. Matuo, T., and Snyder, W. C. 1973. Use of morphology and mating populations in the identification of formae speciales in Fusarium solani. Phytopathology 63:562-565.
22. Nakayama, K., and Aoki, T. 2010. Foot rot of tomato, a new disease in Japan, caused by Fusarium solani f. sp. eumartii. Jpn. J. Phytopathol. 76:716.

23. Nelson P. E., Toussoun T. A., and Marasas, W. F. O. 1983. Fusarium Species: An Illustrated Manual for Identification. Pennsylvania State University, University Park.

24. Nirenberg, H. I., and Brielmaier-Liebetanz, U. 1996. Nectria ipomoeae Halst., anamorph: Fusarium striatum Sherb. an Passiflora edulis Sims. Nachrichtenbl. Dtsch. Pflanzenschutzdienst. (Berlin) 48:270-275.

25. Nirenberg, H. I., and O'Donnell, K. 1998. New Fusarium species and combinations within the Gibberella fujikuroi species complex. Mycologia 90:434-458.

26. O'Donnell, K. 2000. Molecular phylogeny of the Nectria haematococcaFusarium solani species complex. Mycologia 92:919-938.

27. O'Donnell, K., and Gray, L. E. 1995. Phylogenetic relationships of the soybean sudden death syndrome pathogen Fusarium solani f. sp. phaseoli inferred from rDNA sequence data and PCR primers for its identification. Mol. Plant-Microbe Interact. 8:709-716.

28. O’Donnell, K., Humber, R. A., Geiser, D. M., Kang, S., Park, B., Robert V. A. R. G., Crous, P. W., Johnston, P. R., Aoki, T., Rooney, A. P., and Rehner, S. A. 2012. Phylogenetic diversity of insecticolous fusaria inferred from multilocus DNA sequence data and their molecular identification via FUSARIUM-ID and Fusarium MLST. Mycologia 104:427-445.

29. O'Donnell, K., Sutton, D. A., Fothergill, A., McCarthy, D., Rinaldi, M. G., Brandt, M. E., Zhang, N., and Geiser, D. M. 2008. Molecular phylogenetic diversity, multilocus haplotype nomenclature, and in vitro antifungal resistance within the Fusarium solani species complex. J. Clin. Microbiol. 46:2477-2490.

30. Romberg, M. K., and Davis, R. M. 2007. Host range and phylogeny of Fusarium solani $\mathrm{f}$. sp. eumartii from potato and tomato in California. Plant Dis. 91:585-592.

31. Rossman, A. Y., Samuels, G. J., Rogerson, C. T., and Lowen, R. 1999. Genera of Bionectriaceae, Hypocreaceae and Nectriaceae (Hypocreales, Ascomycetes). Stud. Mycol. 42:1-248.

32. Schoch, C. L., Seifert, K. A., Huhndorf, S., Robert, V., Spouge, J. L., Levesque, C. A., Chen, W., and Fungal Barcoding Consortium. 2012. Nuclear ribosomal internal transcribed spacer (ITS) region as a universal DNA barcode marker for Fungi. Proc. Natl. Acad. Sci. USA 109:6241-6246.

33. Sherbakoff, C. D. 1915. Fusaria of potatoes. Mem. Cornell Univ. Agric. Exp. Stn. 6:87-270

34. Suga, H., Hasegawa, T., Mitsui, H., Kageyama, K., and Hyakumachi, M 2000. Phylogenetic analysis of the phytopathogenic fungus Fusarium solani based on the rDNA-ITS region. Mycol. Res. 104:1175-1183.

35. Vincelli, P., and Tisserat, N. 2008. Nucleic acid-based pathogen detection in applied plant pathology. Plant Dis. 92:660-669.

36. Wheeler, M. H., Stipanovic, R. D., and Puckhaber, L. S. 1999. Phytotoxicity of equisetin and epi-equisetin isolated from Fusarium equiseti and $F$ pallidoroseum. Mycol. Res. 103:967-973.

37. White, T. J., Bruns, T., Lee, S., and Taylor, J. 1990. Amplification and direct sequencing of fungal ribosomal RNA genes for phylogenetics. PCR Protocols Guide Methods Appl. 18:315-322.

38. Wollenweber, H. W., and Reinking, O. A. 1935. Die Fusarien, ihre Beschreibung, Schadwirkung und Bekämpfung. Paul Parey, Berlin.

39. Zhang, N., Geiser, D. M., and Smart, C. D. 2007. Macroarray detection of solanaceous plant pathogens in the Fusarium solani species complex. Plant Dis. 91:1612-1620.

40. Zhang, N., O’Donnell, K., Sutton, D. A., Nalim, F. A., Summerbell, R. C., Padhye, A. A., and Geiser, D. M. 2006. Members of the Fusarium solani species complex that cause infections in both humans and plants are common in the environment. J. Clin. Microbiol. 44:2186-2190.

41. Zvirin, T., Herman, R., Brotman, Y., Denisov, Y., Belausov, E., Freeman, S. and Perl-Treves, R. 2010. Differential colonization and defence responses of resistant and susceptible melon lines infected by Fusarium oxysporum race 1·2. Plant Pathol. 59:576-585. 